Chronic Obstructive Pulmonary Diseases:

Journal of the COPD Foundation

\title{
Editorial
}

\section{Chronic Obstructive Pulmonary Disease: Reduced Nihilism, But There is Still a Ways to Go}

\author{
Hilary Pinnock, MB ChB, MD, MRCGP ${ }^{1}$ Ratna Sohanpal, BDS, MSc, DDPH, $\mathrm{PhD}^{2}$
}

Abbreviations: chronic obstructive pulmonary disease, COPD; quality adjusted life years, QALYs; forced expiratory volume in 1 second, FEV $_{\mathbf{1}}$; forced vital capacity, FVC

Citation: Pinnock H, Sohanpal R. Editorial-Chronic obstructive pulmonary disease: reduced nihilism, but there is still a ways to go. Chronic Obstr Pulm Dis (Miami). 2016; 3(3): 605-609. doi: http://dx.doi.org/10.15326/jcopdf.3.3.2016.0151

1 Allergy and Respiratory Research Group, Usher Institute for Population Health Sciences and Informatics, The University of Edinburgh, United Kingdom

2 Centre for Primary Care and Public Health, Blizard Institute, Queen Mary University of London, United Kingdom

\section{Address correspondence to:}

Professor Hilary Pinnock

Professor of Primary Care Respiratory Medicine,

Usher Institute for Population Health Sciences and Informatics,

The University of Edinburgh

Doorway 3, Medical School, Teviot Place,

Edinburgh EH8 9AG

Tel: 01316509474

Fax: 01316509119

E-mail: hilary.pinnock@ed.ac.uk

\section{Keywords:}

COPD; professional attitudes

\section{Burden of Disease}

People with chronic obstructive pulmonary disease (COPD) live with a gradually increasing burden of disabling physical symptoms (especially breathlessness), compounded by comorbidities, psychological distress and social isolation. ${ }^{1-3}$ Historically, the needs of people with COPD have been poorly addressed by health care services. ${ }^{4}$ Yawn et al in this issue of Chronic Obstructive Pulmonary Diseases: Journal of the COPD Foundation are right to highlight therapeutic nihilism as a barrier and to welcome dramatically improved attitudes and beliefs amongst primary care professionals attending training courses. ${ }^{5}$

\section{'Silence' of Patients and Professional Nihilism}

Definitions of the word nihilism emphasize rejection of reality and meaning, ${ }^{6}$ which may seem extraordinary in the context of a disease with such a profound burden on patients and health care services. Yet, professional nihilism mirrors a recognized tendency for people with COPD to remain silent about their physical and social disabilities, ${ }^{7,8}$ challenging us to consider why, in contrast to many other conditions, COPD seems to attract such inertia.

Qualitative research has highlighted that the disabling symptoms and psychosocial consequences develop imperceptibly with no clear beginning; a lifetime of slow, but inexorable decline punctuated by exacerbations. ${ }^{2,8}$ Patients tend to normalize their limitations as the result of old age, ${ }^{8}$ about which "nothing can be done."7 Recalibration of expectations as an adaptive coping strategy, ${ }^{2,9}$ may contribute to an undemanding acceptance of their circumstances. ${ }^{8,10}$

There is some evidence documenting the perceptions of professionals about COPD and exploring why therapeutic nihilism has been such a feature. The perception of COPD as the self-inflicted result of lifestyle choice, ${ }^{11}$ patients' resistance to treatment and reluctance to accept help, ${ }^{12}$ and a lack of drugs that can slow or reverse the process, are beliefs that shape attitudes, but in addition there is some evidence that clinicians share the tendency to normalize the situation. ${ }^{8}$ Primary care professionals, who may have been providing care for a person with COPD for a decade or 
more, may scarcely notice the slow deterioration in their patient over the years and unwittingly collude with the silence. Professionals and patients may both adapt their perceptions of needs and what it is possible to achieve.

Models of care for people with COPD, therefore, need to be proactive, assess physical, psychological, social and spiritual needs, and facilitate palliation of symptoms and provision of care according to needs that evolve over a lifetime. For professionals this is more than overcoming therapeutic nihilism; a conscious decision to adopt a holistic approach through patient collaboration and partnership is required. ${ }^{12}$

\section{Physical, Psychological, Social and Spiritual Care Needs}

Recent advances in pharmacological treatments that enable physical disability (especially breathlessness) to be eased and exacerbations reduced may have contributed to the reduction in nihilism as both professionals and patients realize that "something can be done." 13 Pulmonary rehabilitation relieves dyspnea and fatigue, improves emotional function and enhances the sense of control that individuals have over their condition $^{14}$; findings that were reflected in positive responses from $80 \%$ of the respondents to Yawn et al's survey. More challenging to manage are the social impacts of the disease. An international survey of people of working age in 6 countries revealed that 40\% had retired prematurely on health grounds incurring estimated lifetime income losses of $\$ 316,000 .^{1}$ As lung function deteriorates, the impact on quality of life and activities of daily living increases, resulting in social isolation both for the patient and their caregiver. ${ }^{2,8}$ Holistic support should cover all aspects of the disease and be offered routinely throughout the life-long course of the disease as an integral component of good management of a long-term condition. ${ }^{10}$

\section{Addressing Tobacco Dependence}

A major omission from Yawn et al's survey is a question about attitudes towards smoking. As the only intervention that will improve the long-term prognosis of COPD, ${ }^{12}$ supporting smoking cessation is not only vital for the individual but is a cost effective intervention for health care systems. The London Respiratory Team's value pyramid estimates the cost per Quality Adjusted Life Years (QALY) of providing smoking cessation as a fraction of the cost of triple therapy with bronchodilators and inhaled steroids (see Figure 1). ${ }^{15}$ Again, attitudes will need to change. Redefining smoking as a relapsing long-term condition of tobacco dependence that can be addressed with behavioral support plus pharmacotherapy may help to overcome professional nihilism and encourage clinicians routinely to ask, advise, assess, assist and arrange support for people with COPD (and many other smoking-related conditions) who wish to quit.

\section{Multimorbidity is the Norm}

The respondents in Yawn et al's paper highlighted that patients may fail to report increasing dyspnea if they attribute their increasing symptoms to other long-term conditions. ${ }^{5}$ Similarly, professionals may struggle to establish the relative contributions of COPD, heart failure and anxiety to patients' symptoms of breathlessness. Multimorbidity is not an uncommon scenario; most people with COPD have at least one additional long-term condition, and many will have multiple morbidities with confusing or contradictory lifestyle and treatment demands. ${ }^{16}$ Relevant evidencebased advice on management of multimorbidity is scarce with most trials and guidelines focusing on the treatment of single diseases, though the international COPD guidelines are an important exception with a chapter on common comorbidities. ${ }^{13}$

\section{Figure 1. The Pyramid of Value for COPD Interventions}

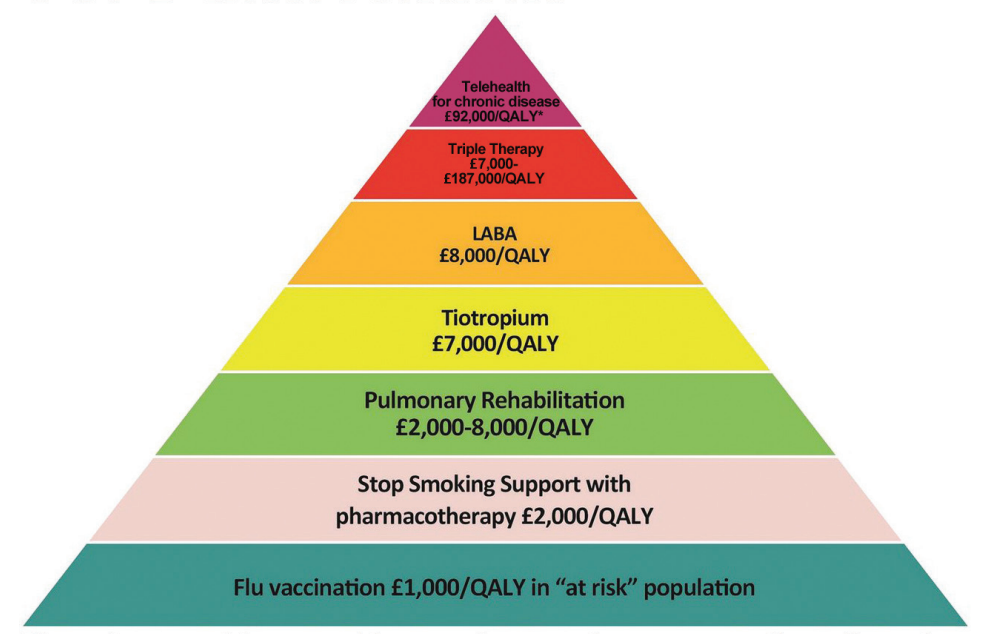

The values on this pyramid are estimates of cost per quality adjusted life year gained.

Note: this version of the pyramid was modified by Zaid Zoumot et al. Emphysema: time to say farewell to therapeutic nihilism. Thorax 2014;69: 973-975 from work done by the London Respiratory Network with The London School of Economics. ${ }^{14}$ 
Providing individually tailored advice for people with multimorbidity is a key role of the generalist family physician who is well placed to review polypharmacy and guide patients through (potentially conflicting) management strategies. ${ }^{17}$ For example, troublesome arthritis may prevent the exercise that will benefit the COPD. Pulmonary rehabilitation improves exercise tolerance and quality of life, ${ }^{14}$ and can improve psychological morbidity, ${ }^{18}$ but patients with depression may not accept referral, or fail to complete the course. ${ }^{19}$ Professionals should initiate a dialogue about the social and psychological benefits of pulmonary rehabilitation along with discussions of the the improved functioning it provides. ${ }^{20}$

\section{Spirometry and/or Symptoms}

In line with guideline recommendations, $85 \%$ of the physician respondents to the survey considered spirometry to be "important" in establishing a diagnosis of COPD. ${ }^{5}$ The quarter of professionals who said that they used trials of bronchodilators or inhaled steroids may, of course, have been trying to exclude asthma (an important differential diagnosis), though it is not clear from the responses whether the success (or otherwise) of the trial was judged by repeated spirometry or symptomatic improvement.

Reliance on symptoms may reflect lack of easy access to spirometry, but it may also reflect a concern amongst the clinicians that lung function is not the only important parameter to measure. International guidelines have adopted a fixed forced expiratory volume in 1 second/ forced vital capacity (FEV $1 / F V C$ ) ratio as their definition of obstruction which overlooks the natural fall in the ratio as a result of normal ageing, ${ }^{21}$ and risks classifying normal elderly as having COPD. A study from a primary care population in Sweden classified $22.5 \%$ of the participants (aged 60-93yrs) as having COPD using a fixed $\mathrm{FEV}_{1} / \mathrm{FVC}$ ratio, compared to $10.1 \%$ using lower limit of normal. ${ }^{22}$ Primary care clinicians are likely to be aware of the risk of medicalizing old age, and may wish to follow the advice of the U.K. guideline and interpret objective measurement of lung function in the light of symptoms. $^{23}$

\section{Person-Centered Consultation Skills}

Yawn et al's survey was conducted during a continuing medical education event prior to a 60-90 minute update on COPD management. Knowledge imparted in a lecture, however, will not be sufficient to enable clinicians to provide patient-centered consultations in order to tailor care to the needs, preferences and goals of the individual. Provision of training in communication, motivational interviewing and behavior change skills are needed to facilitate a holistic focus on patient health. ${ }^{24}$ Audit and feedback can support the practice of newly learnt skills and facilitate a change in clinical practice and improved delivery of patient-centered care. ${ }^{25}$ Professionals trained to work in partnership with patients, can support patients to become more knowledgeable, capable, confident and motivated to make the changes that will improve their day-to-day condition and health. ${ }^{26}$

\section{Conclusion}

COPD is a major cause of disability and there is no place for nihilism. However, if we are to optimize the potential benefits there is a need to look beyond therapeutic nihilism to tackling tobacco dependence and addressing the (often unspoken) psychological, social and spiritual needs of people with COPD. Primary care with its focus on multimorbidity and the individual patient within their family is well placed to take on the challenge. The marked change in attitude between 2007 and 2014 is encouraging: but if we are truly to make a difference in the lives of people with COPD and their families, it does not go far enough. 


\section{References}

1. Fletcher MJ, Upton J, Taylor-Fishwick J, et al. COPD uncovered: an international survey on the impact of chronic obstructive pulmonary disease [COPD] on a working age population. BMC Pub Health. 2011;11:612.

doi: http://dx.doi.org/10.1186/1471-2458-11-612

2. Giacomini M, DeJean D, Simeonov D, Smith A. Experiences of living and dying with COPD: a systematic review and synthesis of the qualitative empirical literature. Ont Health Technol Assess Ser. 2012;12:1-47

3. Lynn J. Ely EW. Zhong Z, et al. Living and dying with chronic obstructive pulmonary disease. J Am Geriatrics Soc. 2000;48 (Suppl 1):S91-S100.

doi: http://dx.doi.org/10.1111/j.1532-5415.2000.tb03147.x

4. Gore JM, Brophy CJ, Greenstone MA. How well do we care for patients with end stage chronic obstructive pulmonary disease (COPD)? A comparison of palliative care and quality of life in COPD and lung cancer. Thorax. 2000;55(12):1000-1006. doi: http://dx.doi.org/10.1136/thorax.55.12.1000

5. Yawn BP, Wollan PC, Textor KB, Tawn RA. Primary care physicians', nurse practitioners' and physician assistants' knowledge, attitudes and beliefs regarding COPD: 2007 to 2014. Chronic Obstr Pulm Dis (Miami). 2016;3(3):628-635. doi: http://dx.doi.org/10.15326/jcopdf.3.3.2015.0168

6. Oxford University Press. Definition of nihilism. Oxford Dictionary website. http://www.oxforddictionaries.com/definiti on/english/nihilism Published 2016. Accessed June 2016

7. Habraken JM, Pols J, Bindels PJE, Willems DL. The silence of patients with end-stage COPD: a qualitative study. $\mathrm{Br} J \mathrm{Gen}$ Pract. 2008;58:844-849.

doi: http://dx.doi.org/10.3399/bjgp08X376186

8. Pinnock H, Kendall M, Murray S, et al. Living and dying with severe chronic obstructive pulmonary disease: multi-perspective longitudinal qualitative study. BMJ. 2011;342:d14.

doi: http://dx.doi.org/10.1136/bmj.d142

9. Kendall M, Buckingham S, Ferguson S, et al. Exploring the concept of need in people with very severe chronic obstructive pulmonary disease: a qualitative study. BMJ Support Palliat Care. [Published Online First: August 26, 2015]

10. Buckingham S, Kendall M, Ferguson S, et al. HELPing older people with very severe chronic obstructive pulmonary disease (HELP-COPD): piloting a practical intervention. NPJPrim Care Respir Med. 2015;25:15020.

doi: http://dx.doi.org/10.1038/npjpcrm.2015.20

11. Barr RG, Celli BR, Martinez FJ, et al. Physician and patient perceptions in COPD: the COPD Resource Network Needs Assessment Survey. Am J Med. 2005;118(12): 1415. doi: http://dx.doi.org/10.1016/j.amjmed.2005.07.059
12. Robinson A, Courtney-Pratt H, Lea E, et al. Transforming clinical practice amongst community nurses: mentoring for COPD patient self-management. J Clin Nursing. 2008;17(11): 370-379. doi: http://dx.doi.org/10.1111/j.1365-2702.2008.02279.x

13. Global initiative for chronic Obstructive Lung Disease (GOLD). Global Strategy for the Diagnosis, Management and Prevention of COPD, 2016. GOLD website. http://goldcopd.org Published 2016. Accessed June 2016.

14. McCarthy B, Casey D, Devane D, Murphy K, Murphy E, Lacasse Y. Pulmonary rehabilitation for chronic obstructive pulmonary disease. Cochrane Database of Syst Rev. 2015, Issue 2. Art. No.: CD003793.

doi: http://dx.doi.org/10.1002/14651858.CD003793.pub3

15. British Thoracic Society/Primary Care Respiratory Society UK. IMPRESS Guide to the relative value of COPD interventions-British Thoracic Society Reports, 2012. IMPRESS website http://www.impressresp.com/index.php?option=com_content\& view=article\&id=167:impressions-28-relative-value-of-copd-inter ventions\&catid $=11$ :impressions\&Itemid $=3$

Published 2012. Accessed June 2016.

16. Barnett K, Mercer S W, Norbury M, Watt G, Wyke S, Guthrie B. Epidemiology of multimorbidity and implications for health care, research, and medical education: a cross-sectional study. Lancet. 2012; 380(9836): 37-43. doi: http://dx.doi.org/10.1016/S0140-6736(12)60240-2

17. Morrison D, Agur K, Mercer S, Eiras A, González-Montalvo JI, Gruffydd-Jones K. Managing multimorbidity in primary care in patients with chronic respiratory conditions. NPJPrim Care Respir Med. 2016. In press.

18. Coventry PA, Hind D. Comprehensive pulmonary rehabilitation for anxiety and depression in adults with chronic obstructive pulmonary disease: Systematic review and meta-analysis. $J$ Psychosomat Res. 2007;63(5):551-565. doi: http://dx.doi.org/10.1016/j.jpsychores.2007.08.002

19. Hogg L, Garrod R, Thornton H, McDonnell L, Bellas H, White P. Effectiveness, attendance, and completion of an integrated, system-wide pulmonary rehabilitation service for COPD: prospective observational study. COPD. 2012; 9(5): 546-554. doi: http://dx.doi.org/10.3109/15412555.2012.707258

20. Sohanpal R, Steed E, Mars T, Taylor S SJC. Understanding patient participation behaviour in studies of COPD support programmes such as pulmonary rehabilitation and selfmanagement: a qualitative synthesis with application of theory. NPJ Prim Care Respir Med. 2015;25:15054.

doi: http://dx.doi.org/10.1038/npjpcrm.2015.54

21. Schermer TRJ, Quanjer PH. COPD screening in primary care: who is sick? Prim Care Respir J. 2007; 16: 49-53. doi: http://dx.doi.org/10.3132/pcrj.2007.00012 
22. Szanto O, Montnemery P, Elmstahl S. Prevalence of airway obstruction in the elderly: results from a cross-sectional spirometric study of nine age cohorts between the ages of 60 and 93 years. Prim Care Respir J. 2010; 19: 231-236.

doi: http://dx.doi.org/10.4104/pcrj.2010.00011

23. National Clinical Guideline Centre. Chronic obstructive pulmonary disease: management of chronic obstructive pulmonary disease in adults in primary and secondary care. London: National Clinical Guideline Centre. 2010. National Institute for Health and Care Excellence website. http:// guidance.nice.org.uk/CG101/Guidance/pdf/English. Published 2010. Accessed June 2016.

24. Walters J, Cameron-Tucker H, Wills K et al. Effects of telephone health mentoring in community-recruited chronic obstructive pulmonary disease on self-management capacity, quality of life and psychological morbidity: a randomised controlled trial. BMJ Open. 2013; 3:e003097.

doi: http://dx.doi.org/10.1136/bmjopen-2013-003097

25. Taylor CA, Shaw RL, Dale J, French DP. Enhancing delivery of health behaviour change interventions in primary care: A metasynthesis of views and experiences of primary care nurses. Pat Ed Counsel. 2011;85(2):315-322.

doi: http://dx.doi.org/10.1016/j.pec.2010.10.001

26. Cameron-Tucker H, Joseph L, Walters J. Health selfmanagement support training positively changes practice for nurses in primary care. Respirology. 2013; 18: 10-37 